\title{
CoNf- $961139--1$ \\ Assessment Techniques for a Learning-centered Curriculum: Evaluation Design for Adventures in Supercomputing
}

\author{
Barb Helland \\ Ames Laboratory* \\ Ames, Iowa 50011
}

\author{
Barbara G. Summers \\ Oak Ridge National Laboratory** \\ Oak Ridge, Tennessee 37831
}

\footnotetext{
* Managed by lowa State University, under contract W-7405-Eng-82 for the US Department of Energy (DOE)

** Managed by Lockheed Martin Energy Research Corporation, under contract DE-AC05-960R22464 for the US DOE
}

\section{Abstract}

As the classroom paradigm shifts from being teacher-centered to being leamer-centered, student assessments are evolving from typical paper and pencil testing to other methods of evaluation. Students should be probed for understanding, reasoning, and critical thinking abilities mather than their ability to retum memorized facts.. The assessment of the Department of Energy's pilot program, Adventures in Supercomputing (AiS), offers one example of assessment techniques developed for leamer-centered curricula.

The goals and objectives that are central to student learning in the Adventures in Supercomputing program [http://anarchy.k12.ames.ia.us/AiS/national] involve the acquisition of thinking and problem-solving skills. During the school year, students are involved in a year-long computational science project. To complete the project students employ the following tools: 1) the Intemet 10 aid in researching their topics and communicating with their mentors, 2) computers to develop and test models of the problems, and 3) visualization software to understand their data. From these resources, students must pose hypotheses, devise methods for solutions, conduct appropriate simulations, and draw proper conclusions.

The assessment of the AiS program has employed a variety of methods to collect student data. Methods of assessment used were traditional testing. performance testing, interviews, short questionnaires via email, and student presentations of projects.

The data obiained from these sources have been analyzed by a professional assessment team at the Center for Children and Technology. The results have been used to improve the AiS curriculum and establish the quality of the overall Ais program. This paper will discuss the various methods of assessment used and the results.

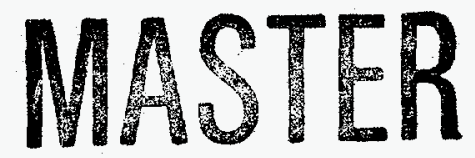

\section{Program Background}

The goal of the AiS program is to foster and enhance the participation of diverse populations of high school students in mathematics, science, and computing.

In 1992 Iowa, New Mexico, and Tennessee piloted the AiS program funded by the DOE's Mathematical, Information, and Computational Sciences Division. Alabama and Colorado were ackled in 1993. During 1992-94, schools applied through a formal application process. A selection committee established in each state reviewed the applications and made the selections. These host states coordinate the AiS program in 70 high schools and 8 middle schools.

\section{Program Elements}

Teacher Training: Initially, leachers on the AiS team in each school receive two weeks intensive training during the Summer Institute. In addition, two workshops and follow-up week-long summer institutes are held to provide training on new technologies and strategies to infuse the technology into the classroom.

Curriculum: The AiS curriculum is a learnercentered computational science course which cuts across the disciplines of mathematics, science, and engineering and fosters the use of computers and technology as tools to simulate a variety of complex, real world problems. To provide the focus for the AiS class, students work in teams to devclop a ycar-long project. Teachers ane encouraged to serve as facilitalors of learning, to guide their students to research appropriate materials and to acquire mentors who will help students define and focus their project. The students' progression on their projects resembles the manner in which real research teams approach solving problems.

To promote the use of AiS in the classroom, a high school computational science textbook has been 


\section{DISCLAIMER}

Portions of this document may be illegible in electronic image products. Images are produced from the best available original document. 
developed for the World Wide Web (WWW). The on-line textbook and teachers' manual will provide a curriculum that will aid in supporting a high school computational science course. Specific modules of the textbook may also be integrated into other content areas. The textbook's URL is: http://k12.colostate.edu/textbook/textbook.html

Technical support is provided for the schools involved in the AiS program. Since the schools are required to maintain a class in computational science, it is critical that they do not experience any down time due to equipment failure or software questions. An experienced technical consultant, who is also knowledgeable of the AiS program and curriculum, assists the teachers throughout the year.

Exposition: As noted earlier, each year student teams work on projects dealing with real world problems. The students then exhibit their work via a technical paper, an oral presentation, and a visual display at an annual state Expo. Computational scientists from the host facility and local universities serve as extemal reviewers for the Expo projects to assess the soundness of project ideas, the accuracy of content and the validity of methods and results. The top teams from each state are invited to participate in a National Expo held in Washington, DC in June of each year.

\section{Assessment}

Since the inception of the AiS, the project leaders have recognized the importance of an assessment component. The purpose of the annual assessment was not only to provide an external review of the program but also to provide intermediate feedback to project coordinators to aid them in refining the program, especially the teacher training at the Summer Institute.

During the first year of AiS (1992-1993), the Research Institute for Studies in Education (RISE) at lowa State University conducted a traditional assessment of the twenty schools participating in the AiS program in Iowa, Tennessee and New Mexico. Their assessment activities focused on evaluating the AiS objectives 1) to prepare teachers so they can effectively teach students and 2) to attract/involve underrepresented groups in science, mathematics and computing experiences. A survey instrument based on the Concerns Based Adoplion Model (CBAM) was used to evaluate the teachers' concerns with the AiS program [1]. Bandura's self-efficacy model provided the framework for evaluating attitude and behavior change in students involved in the AiS program [2]. During the 1992-1993 school year the following student evaluation methods were utilized:
- Student background information was collected at the beginning of the year.

- A student attitude questionnaire was administered at the beginning and end of the school year.

- Student feedback about the year was gathered at the end of the year.

Each school in the program was also asked to identify a control group of students that had the same gender and ethnicity distribution as that of the AiS students.

The Executive Summary from the "Adventures in Supercomputing Evaluation Report Academic Year 19921993" indicated that there were positive changes in student attitudes toward mathematics particularly in grades 9 and 10 [3]. Teachers also overcame their concerns about the AiS curriculum by the end of the year and began to focus on the program's impact on students. Interestingly, many students indicated that they would like to participate in AiS again.

Recognizing that the project-based AiS curriculum represented a shift from a teacher-centered to a learner-centered classroom, AiS project leaders sought an external assessment team that would utilize techniques that were more project-based and would employ technology as one of the evaluation platforms. For these reasons, the Center for Children and Technology (CCT) was selected in 1993 to assess the AiS program.

Because teachers' knowledge of and comfort level with any educational innovation is key to its success, CCT docided to focus their assessment on those classes taught by teachers who were beginning their second year in AiS [4]. Thus, the evaluation for the 1993-1994 school year concentrated on the classrooms of teachers who were in the program in 1992-1993 and only in the states of Iowa, New Mexico and Tennessee. Like the RISE evaluation, demographic information was collected to characterize AiS teachers, students and schools. CCT also collected contextual data through site visits to a subset of schools and teacher interviews to investigate the methods teachers used to implement the AiS curriculum. Electronic journals were collected from AiS students on a monthly basis to explore the development of the students' ideas and questions as they worked on their projects. However, the cornerstone of the assessment was the videotaping and scoring of a subset of student project presentations via a crileria developed at CCT. Demographically, the selected subset matched the full pool of students involved in the evaluation. To make the videotaping of the students' projects as authentic and meaningful as possible two steps were taken in early winter: 1) students and teachers were informed about what was expected of them; and 2) representatives from each 
state who were participating in the videotaping process either as questioners and/or videographers' were trained at the Educational Development Center in New York. All taping and questioning was conducted by staff of the three Department of Energy laboratories.

It is also important to insure that the coders of the videotapes understand the AiS goals and objectives as they make judgments of students' performance. For that reason, six coders were selected from the AiS leacher pool in the participating states and received an intensive three day training which focused on hands-on experience in using the coding scheme. At the training workshop, teachers worked in pairs, viewing tapes, discussing responses to them and determining together how to code. them appropriately. Group consensus was reached on codes for each of the tapes used in training.

As mentioned before, the coding scheme is based on criteria developed at CCT. The coding scheme was modified to reflect the aspects of student work most relevant to the goals of the AiS program. The coding rubric involves five dimensions, each of which are ooded on a scale from 1 to 5 , where 1 represents poor work and 5 represents outstanding work. The five scoring dimensions used in the CCT coding rubric are:

- Understanding To what extend do students demonstrate knowledge of their area of inquiry?

- Critical thinking To what extent are students able to be reflective about the challenges and problems they encountered in their project and the larger implications of their work?

- Clarity of presentation To what extent are students able to effectively communicate their ideas to others?

- Teamwork To what extent do the students work collaboratively on substantive aspects of the project?

- Technical competence To what extent are students able to apply programming skills to analyze or investigate their area of interest?

During the scoring of the actual AiS student presentations, all tapes were randomly distributed to the coders and each tape was scored by two independent coders. One point discrepancies between coders were resolved by averaging the scores and 2 and 3 point discrepancies were resolved by the researchers at CCT who examined the coders' supporting statements. The overall reliability of the scores in the 1993-94 assessment was $80 \%$.
Student scores on the videotaped presentations were then grouped into clusters that describod different types of performance. Researchers compared the information from the demographic and process learning data and identified those components that could be correlated to the differences among clusters of student performances. The AiS videotaped presentations for 19931994 were grouped into three distinct clusters based on distinct means across the five dimensions of scoring. The three clusters were characterized as follows:

- Integrated Knowledge Students in this category were successful in applying computational techniques to a well-defined set of questions. The mean scores for critical thinking, clarity, teamwork and technical competence were consistent across this group. There were $51 \%$ of the students videotaped in this category.

- Procedural Knowledge Students in this category basically fulfilled project requirements, but displayed little ability to reflect upon or explain the implications of their work. Thirty-four percent of the students were in this category.

- Fragmented Knowledge Students in this category were unable to develop a well-defined problem that could be translated to a computational model. The mean scores in this category were more diverse than the other two groups. Fifteen percent of the students fell in this calegory.

Interestingly, after taking contextual data into account, the researchers at CCT found that group size and group composition by sex were important factors in the student projects. For example, all-female and mixed-sex groups were significantly correlated with being in the Integrated Knowledge group.

The 1994-1995 assessment conducled by CCT was similar to their 1993-1994 assessment except for the following:

- All five states in the program were involved in the assessment.

- The assessment involved a subset of the schools involved in the 1993-1994 assessment (schools involved in AiS for three years) plus the second year schools from Alabama and Colorado.

- Demographic information was collected on all schools in the program.

- Because of the difficulty the coders had in determining the answers to items that made up thcir coding scheme, videographers and questioners were provided 
with a set of questions to ask each student presentation team.

The overall reliability of the $1994-1995$ scores was $88 \%$. The results of the scorers were again grouped into clusters. However, the clusters did not represent the same categories as in the 1993-1994 assessment. In 1994-1995, all the clusters exhibited consistent scores across understanding, critical thinking, a slightly higher teamwork score and slightly lower technical competency score. The clusters differ from each other in the level of the mean scores that they include: the High cluster (37\% of students) reflects above average to outstanding scores; the Middle Cluster (35\% of students) reflects scores midway between average and above average; the Low Cluster (27\% of the students) includes average to slightly below average scores.

When compared to the contextual data gathered through site visits and teacher interviews, it is apparent that as teachers gain more experience with AiS and with technological tools, they are more successful in supporting students' efforts to create successful computational science projects. Also students with previous programming experience were most likely to fall in the High Cluster.

\section{Assessment Tools for AiS Classes}

The 1995-1996 school year represented the fifth year of the AiS pilot. Instead of conducting a third year of the performance based assessment, the project leaders asked CCT to develop assessment tools to assist teachers when implementing the AiS curriculum.

Needs: With a project intensive course, teachers see a need to assess students in a variely of ways. Teachers have used performance assessments or practical exams, group conferences, and reflective journalling to help them assess the projects developed in the AiS course. However, they need to have a more structured, systematic way of looking at the students work, similar to the rubric the coders used for analyzing the videotaped student projects.

Project Portfolio: The template being designed by CCT consists of three main modules: (1) the Verbal Narrative Mode, (2) the Concept Mapping Mode, and (3) the Graphical Representation Mode [5]. In the verbal narrative mode, the students are questioned to help them communicate and clarify the main ideas of their projects. In the concept mapping mode, the students brainstorm important concepts of their projects and then draw a concept map identifying the necessary links between the concepts. In the final mode, the students upload their maps into a Gallery environment which is accessible to their teachers and mentors via the WWW.

As teachers use concept mapping in each stage of project development, they will be able to visually see if the students are making the correct links between the concepts in their projects. By using the concept maps, teachers and mentors will be able to understand how the students are organizing, relating and synthesizing the research information they are gathering [6]. It is important that students establish the proper links between the concepts related to their project. The concept map requires learners to think more acutely about the subject matter and demands some cognitive reflection.

\section{Lessons Learned}

The wealth of dala that has been collected in conjunction with the assessment of the AiS program has allowed the project leaders to develop training modules and curriculum that enhance the implementation of AiS in the classroom. For example, the 1993 interim report by CCT indicated that there needed to be more emphasis placed on project development. The 1994 Summer Institute was structured to reintroduce AiS concepts in the context of project development and group investigations. By gaining a clearer understanding of the problems that the students address when researching and implementing their projects, the project leaders and teachers work together to develop support systems for students.

\section{References}

1. Hall, G.E., Wallace, R. C. Jr., \& Dossett, W. A. "A development conceptualization of the adoption process within educational institutions." Austin: Research and Development Center for Teacher Education, The University of Texas, 1973

2. Bandura A. (1977). Self-efficacy: Toward a Unifying Theory of Behavioral Change. Psychological Review, $84,191-215$.

3. RISE report

4. Sheingold, K. \& Hadley, M. "Accomplished Teachers: Integrating computers into classroom practice; Education Development Center: New York. 1990

5. Honey, M.; McMillian, K. \& Tsikalas, K. "Design Document: Development of Assessment Tolls for Use in AiS Classes." 1996. CCT. Draft Document

6. Jonassen, D. "Concept Mapping and Other Formalisms as Mindtools for Representing Knowledge." http://www.icbl.hw.ac.uk/ granum/granum.html 